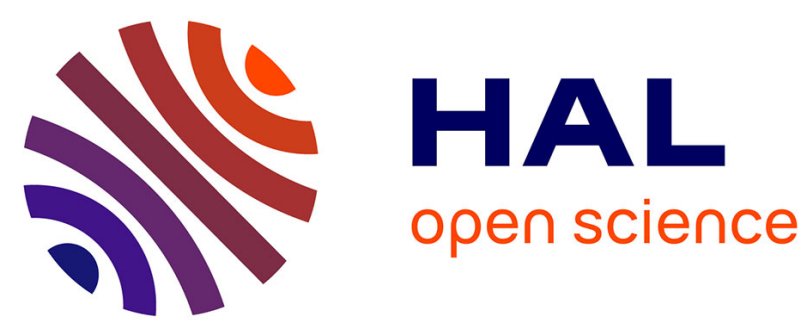

\title{
INTERNAL STRESS MEASUREMENT IN ALUMINIUM BY "DIP-TEST" METHOD AND CORRELATION WITH THE BORDONI RELAXATION EVOLUTION
}

J. Chicois, A. Hamel, R. Fougères, C. Esnouf, Gilbert Fantozzi, J. Perez

\section{To cite this version:}

J. Chicois, A. Hamel, R. Fougères, C. Esnouf, Gilbert Fantozzi, et al.. INTERNAL STRESS MEASUREMENT IN ALUMINIUM BY "DIP-TEST" METHOD AND CORRELATION WITH THE BORDONI RELAXATION EVOLUTION. Journal de Physique Colloques, 1981, 42 (C5), pp.C5-169C5-173. 10.1051/jphyscol:1981526 . jpa-00221068

\section{HAL Id: jpa-00221068 https://hal.science/jpa-00221068}

Submitted on 1 Jan 1981

HAL is a multi-disciplinary open access archive for the deposit and dissemination of scientific research documents, whether they are published or not. The documents may come from teaching and research institutions in France or abroad, or from public or private research centers.
L'archive ouverte pluridisciplinaire HAL, est destinée au dépôt et à la diffusion de documents scientifiques de niveau recherche, publiés ou non, émanant des établissements d'enseignement et de recherche français ou étrangers, des laboratoires publics ou privés. 
JOURNAL DE PHYSIQUE

colzoque C5, supplément au n¹0, Tome 42, octobre 1981

page $\mathrm{C5}-169$

\title{
INTERNAL STRESS MEASUREMENT IN ALUMINIUM BY "DIP-TEST" METHOD AND CORRELATION WITH THE BORDONI RELAXATION EVOLUTION
}

\author{
J. Chicois, A. Hame1, R. Fougères, C. Esnouf*, G. Fantozzi* and J. Perez* \\ Laboratoire de Métallurgie et Traitements Thermiques, Bât. 303 \\ * Groupe d'Etudes de Métazlurgie Physique et Physique des Matériaux, E.R.A. 463 \\ Bât. 502, Institut National des Sciences Appliquées de Lyon - 69621 \\ Vizzeurbonne Cedex, France
}

\begin{abstract}
The Bordoni relaxation appears only with a sufficient value of stress given by the Paré condition. We have made a direct measurement of internal stress in order to know its evolution during plastic deformation or annealing. This evolution is compared with the behaviour of the Bordoni relaxation : variation of the relaxation strength on the one hand and non linear properties on the other hand.
\end{abstract}

1. Introduction.- It is well established that the Bordoni relaxation strength is related to the stress amplitude (1). Indeed, the Bordoni peaks appear only when the Paré condition is fullfilled : $\sigma b^{2} \ell \approx 2 \mathrm{w}_{\mathrm{k}}(1)$ with $\sigma=\sigma_{i}+\sigma_{\mathrm{m}}$ ( $\sigma_{i}$ internal, $\sigma_{\mathrm{m}}$ applied stress), $\ell=$ dislocation length and $2 W_{k}=$ double-kink nucleation energy. During plastic deformation or annealing, the height of the Bordoni peaks changes and this change can be due either to the variation of dislocation length or the variation of internal stress. This second variation is often neglected. Thus, is is interesting to have a direct measurement of internal stress in order to know its evolution during plastic deformation or annealing and to compare with the behavioux of the Bordoni relaxation. In particular, we have studied simultaneously the change of internal stress and the non linear properties of the Bordoni relaxation, which are correlated with the value of internal stress.

\section{Experimental results}

i : internal stress

By dip test method, internal stress is determined on polycristalline thin tubes of aluminium $99.999 \%$. The study itself is concerned with torsional creep tests. Maximum stress gradient is smaller than $10 \%$ of maximum applied stress. The internal stress measurements are made with a special test machine, suitable for this test type $(2)$. The measurements of the creep strain are carried out with a special sensitive captor, fixed on the sample itself. This apparatus allows to detect a strain value as low as $10^{-7}$ (2). Samples are then submitted to an annealling at $525 \mathrm{~K}$ during one hour after a cross section reduction of $70 \%$.

Maximum creep rate are plotted versus successive values of the applied stress in $\mathrm{fig}$. 1. This curve presents two ranges : the low stress range is due to an anelastic process and the high stress range is linked to a microplastic strain process. Similar results have been obtained on iron carbon alloys ( 3 ). In the high stress range, the stress corresponding to zero creep rate for different creep strain values is determined. As it will schow below, the obtained stress values are very closed to internal stress ones. The stress obtained by extrapolation at zero total creep strain is the internal stress which is typical of the microstructural state of the specimen. 
Figure 2 represents the evolution of creep rate $\dot{\varepsilon}_{g}$ as a function of applied stress values under unloading conditions.

In this case, the creep strain, equal to $3.3 .10^{-4}$, is very lower than the preplastic shear strain $\left(2 \cdot 10^{2}\right)$. Assuming that the evolution of anelastic creep rate law is identical under loading and unloading conditions, error value due to the anelastic process is determined according an analysis method described elsewhere (4). Internal stress $\tau_{i}$ is always measured with a precision better than $2 \%$. Internal stress value is closed to applied stress one. It is in good agreement with the fact that thermal stress component is very weak in aluminium at room temperature. For a preplastic deformation of $2.10^{2}$, internal stress is plotted versus total creep strain (fig. 3). Typical internal stress of the microstructure aspect of specimen is obtained by extrapolation at zero total creep deformation. For several preplastic deformation, evolution of typical internal stresses is shown in fig. 4. Moreover, for a $2 \%$ preplastic strain, the variation of internal stresses with annealing temperature is schown in fig. 5. The stress decrease seems to present two evolution ranges with the annealing temperature : one, between room temperature and $340 \mathrm{~K}$, the other above. At high annealing temperature, internal stress value tends towards internal stress value obtained before preplastic deformation.

\section{i.i : internal friction}

Figures 6 and 7 schow the effect of a static stress $\sigma_{s}$ on the internal friction spectra measured with a vibration stress amplitude lower than $\sigma_{\mathrm{s}}$. We observe that for low plastic deformation the static stress influence is strong (fig. 6) whereas, for important deformation, the Bordoni relaxation behaviour becomes linear (fig. 7 ). Figure 8 shows the effect of annealing on the non linear behaviour of the Bordoni relaxation. We can note that for high temperature annealing, the Bordoni relaxation becomes very sensitive to the amplitude of the applied stress.

3. Discussion.- Internal stresses are due to dislocations which are present in the metal. The relation between internal stress $\tau_{i}$ and dislocation density $N$ is generally given by the following relation :

$$
\tau_{i}=\alpha \sqrt{\mathrm{N}}
$$

with $\alpha$ a constant parameter. From this relation, the internal stress evolution with preplastic deformation is given by :

$$
\tau_{i}-\tau_{i 0}=\alpha\left(\sqrt{\mathrm{N}}-\sqrt{\mathrm{N}_{0}}\right)
$$

with $\tau_{i}$ and $N_{0}$ respectively the initial internal stress and dislocations density values. However, the dislocation density can be deduced from the applied stressplastic deformation curve $\tau, \varepsilon_{p}$ by the following relation (6) :

$$
N=A_{d} \int \tau d \varepsilon_{p}
$$

with $A_{d}$ a constant value.

Using a planimeter, the evolution of the density of dislocation with plastic strain $\varepsilon_{p}$ is determined from experimental $\left(\tau-\varepsilon_{p}\right)$ curve according to relation (4). This evolution can be represented by the following expression :

$$
N=N_{0}+A_{d}^{1} \varepsilon_{p}^{m}
$$

with $m=1.16$. This result is in good agreement with the ones found by others authors (6) and (7).

Assuming $N \gg N_{0}$, relations (3) and (5) can be read as follows :

$$
\tau_{i}-\tau_{i 0} \simeq \alpha \sqrt{N} \quad \text { and } \quad N \simeq A_{d}^{i} \varepsilon_{p}^{m}
$$




$$
\tau_{i}-\tau_{i 0}=K \varepsilon_{p}^{n} \quad \text { with } K \text { a constant. }
$$

$\mathrm{n}$ value is equal to 0.55 which is near of preceding value $(\mathrm{m} / 2=0.58)$.

Finally, these results and the good order of magnitude of dislocation density deduced from relation $(2)\left(\mathrm{egN}_{0} \approx 10^{+6} \mathrm{~cm}^{-2}\right)$ indicate that experimental results are coherent.

on the other hand, the internal friction experiments show that the Pare condition (8) is not satisfied when the plastic deformation is low (fig. 6) or after annealing (fig. 8) because it appears only a badly defined peak without static stress. The application of a bias stress of $5 \times 10^{-5} \mathrm{G}$ reestablished the Paré condition and a well-defined Bordoni peak appears clearly (fig. 6 and 8 ).

However, after annealing, we observe an increase of the Bordoni peak after suppression of $\sigma_{S}$ : thus, the application of $\sigma_{S}$ modifies the internal friction behaviour.

For high plastic deformation, the Pare condition is always fulfilled and the effect of a bias stress is negligible (fig. 7).

By comparison with the internal stress measurements, we can deduce that the non linear behaviour is observed only when the internal stresses are weak. But from the relation ( 1 ) and the experimental results, the Pare condition is satisfied by stresses lower than the internal stress measured by dip test $\left(\approx 5 \times 10^{-5} \mathrm{G}\right.$ instead of $\left.\approx 2 \times 10-4\right)$.

This result can be explained only if the internal stresses distribution is taken into account. Indeed, such distributions have been observed by "in situ" M.E.T. experiments (9). By dip test method, we measure the mean value of internal stresses which can be considered as a "macroscopic" internal stress (10). On the other hand, internal friction is sensitive only to the weakest "local" internal stresses. This discussion allows us to explain the difference between the stress necessary to fulfill the Pare condition and the internal stress deduced from the dip test. Furthermore, the fraction of dislocations submitted to low internal stress values must decrease when the plastic deformation increases.

In conclusion, we have observed a qualitative correlation between the evolution of the internal stresses and the behaviour of internal friction, either after plastic deformation or annealing. Other experiments must be carried out to make more quantitative comparison between these results.

\section{References}

(1) G. Fantozzi, W. Benoit, C. Esnouf and J. Perez, Ann. Phys. Fr., 4, 7 (1979).

(2) A. Hamel, J. Chicois, R. Fougères and M. Théolier, Journal of Physics E, Scientific Instruments, à paraître.

(3) R. Fougères, A. Hamel and M. Théolier, Praceedings of ICSMA 5, Aachen, W. Germany, 1, 337 (1979).

(4) J. Chicois, A. Hamel, R. Fougères and J. Perez, Scripta Met., sous presse.

(5) I. Kovacs and L. Zsoldos, Dislocations and plastic deformations, Pergamon Press, Oxford, p. 251 (1973).

(6) R. W. Honeycombe, The plastic deformation of metals, Edward Arnold (1977).

(7) S. Ceresara, H. E1kholy and T. Federighi, Phys. Stat. So1., 8, 509 (1965).

(8) V. K. Paré, J. Appl. Phys., 3, 332 (1961).

(9) H. Mughrabi, J. Microsc. Spectrose. Electron., 1, 571 (1976).

(10) F. Dobes, Phys. Stat. Sol. (a), 34, K 27 (1976). 


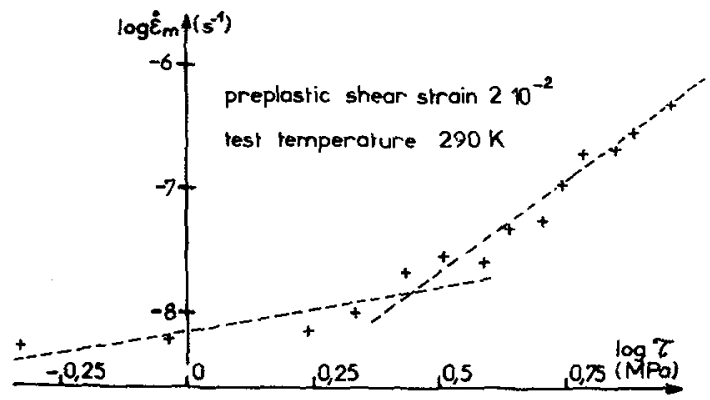

Fig. 1 : Evolution of the logarithm of the maximal creep rate as a function of the 10garithm of the applied stress. Preplastic shear deformation by torsion equal to $2 \times 10^{2}$.

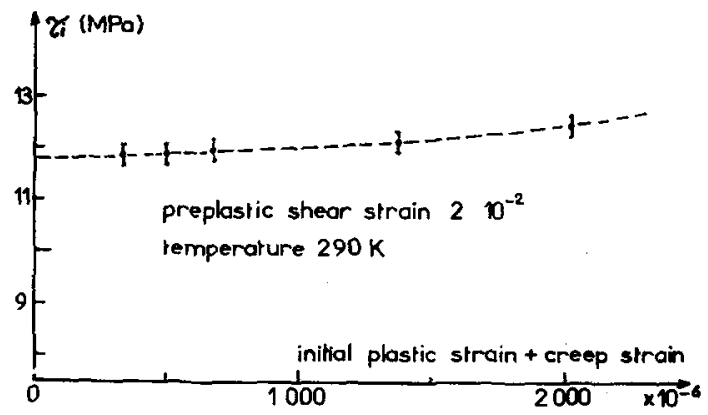

Fig. 3 : Evolution of the internal stress as a function of plastic strain during a creep test.

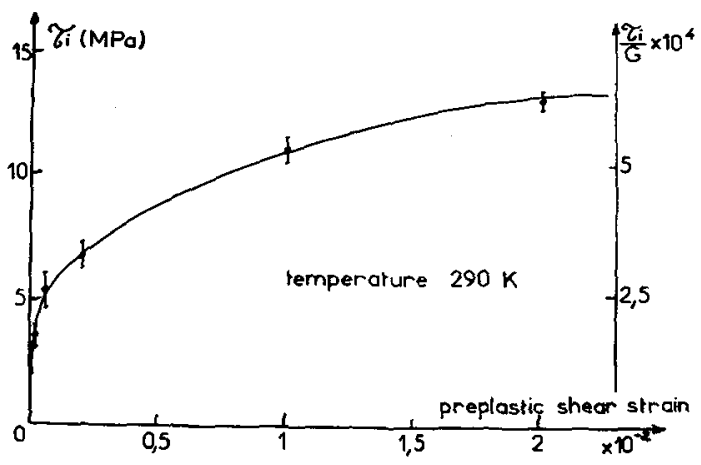

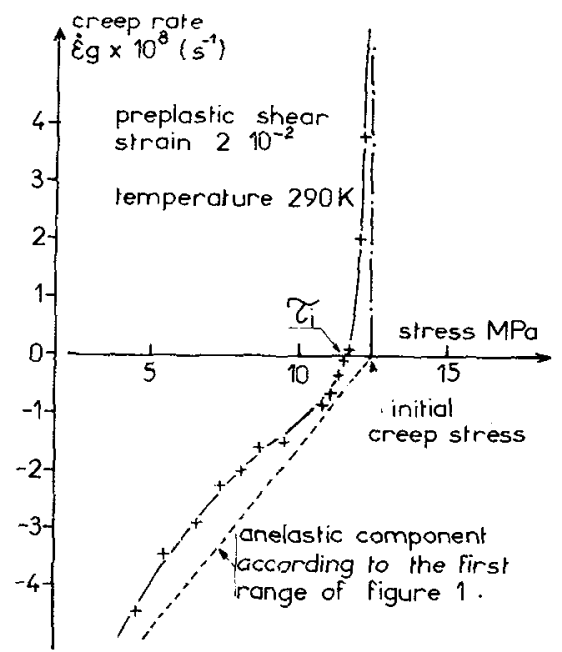

Fig. 2 : Evolution of the creep rate versus applied stress during unloading of the sample by successive steps.
Fig. 4 : Internal stress and ratio of internal stress and shear modulus versus preplastic shear strain by torsion. 

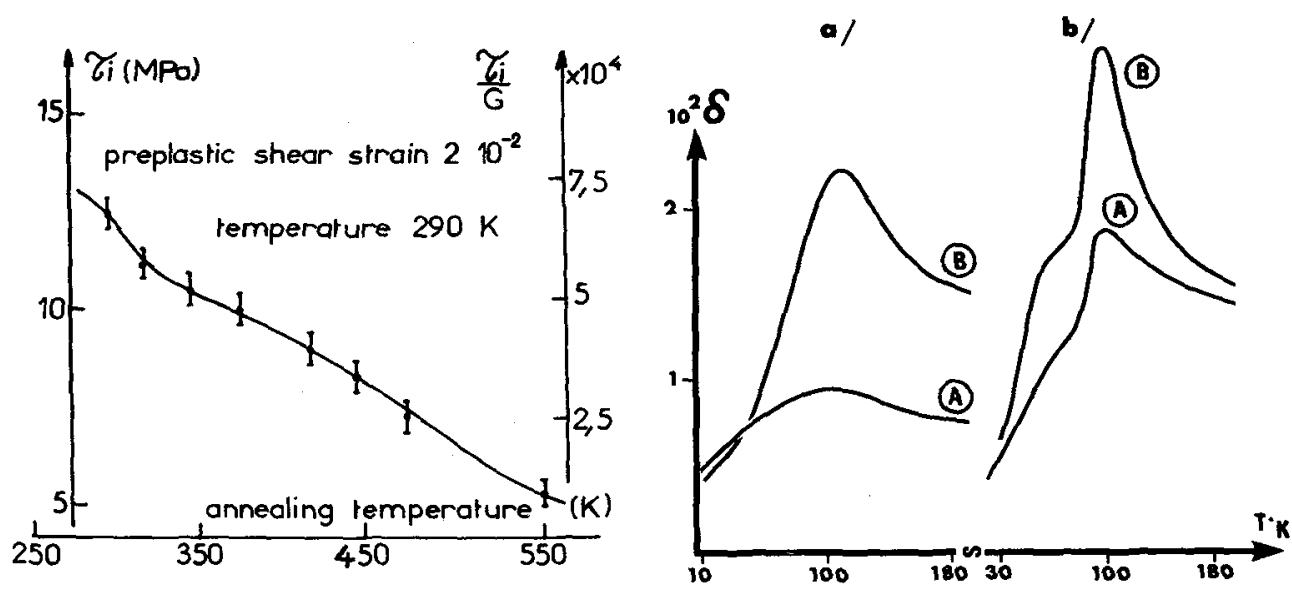

Fig. 5 : Internal stress evolution as a function of the annealing temperature. Duration of the treatment : 1 hour.

Fig. 6 : Internal friction spectra after cold working by torsion of $0.02 \%$ (a) and of $0.05 \%$ (b) at $300 \mathrm{~K}$ : curve $\mathrm{A}$ : without static stress, curve B : with a static stress $\sigma_{S}=5 \times 10^{-5} \mathrm{G}$ (the oscillating strain amplitude is $5 \times 10^{-6}$ and $f \simeq 1 \mathrm{hz}$ ).
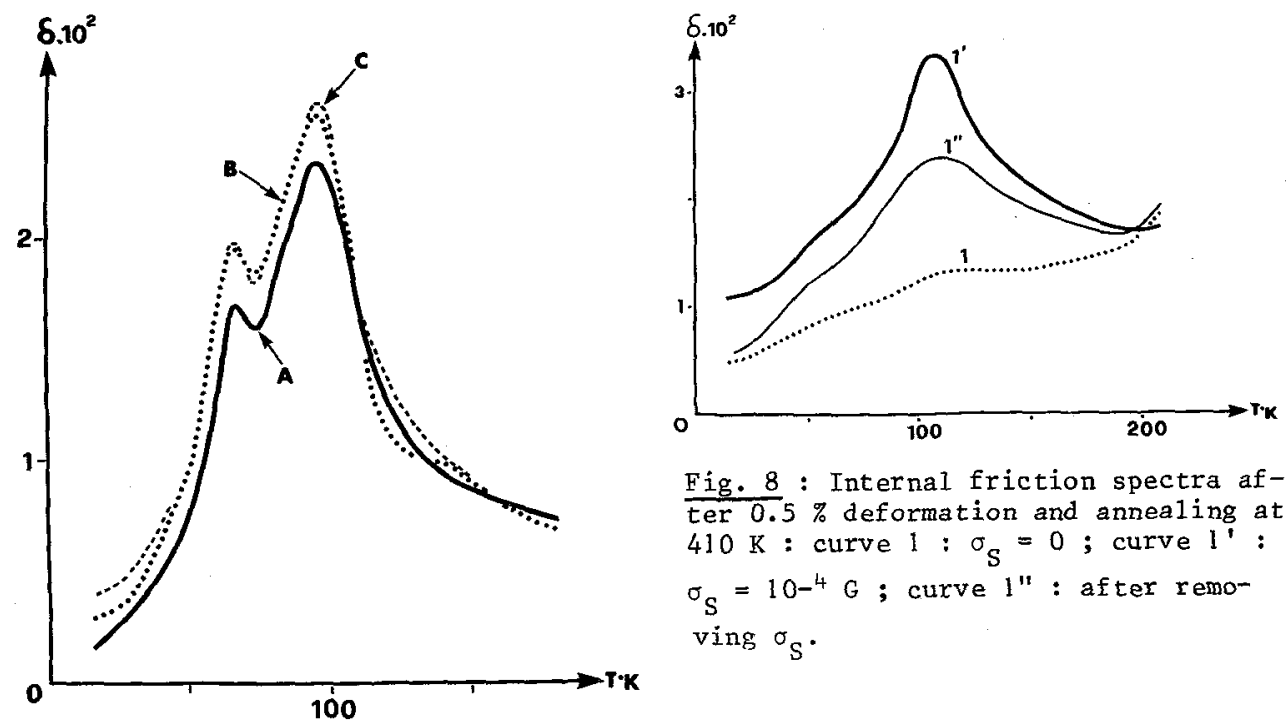

Fig. 8 : Internal friction spectra after $0.5 \%$ deformation and annealing at $410 \mathrm{~K}:$ curve $1: \sigma_{\mathrm{S}}=0$; curve 11 : $\sigma_{S}=10^{-4} \mathrm{G}$; curve $1 "$ : after removing $\sigma_{S}$.

Fig. 7 : Internal friction spectra after $0.5 \%$ plastic deformation at $300 \mathrm{~K}$ : curve A : $\sigma_{S}=0$, curves $B(C)$ $\sigma_{S}=8.9(18.7) \times 10^{-5} \mathrm{G}\left(\varepsilon_{\mathrm{m}}=2 \times 10^{-5}\right.$, $\mathrm{f}=1.7 \mathrm{hz}$ ). 